average CRP was $0.25 \pm 0.36 \mathrm{mg} / \mathrm{dl}$. The test method for the serum $25 \mathrm{OHD}$ concentration was measured with the CLIA antibody method (SRL, Inc.). Regarding the judgment criteria of deficiency, although various discussions are in progress, "the index of serum $250 \mathrm{HD}$ deficiency less than $20 \mathrm{ng} / \mathrm{ml}$ " prepared by the institute of medicine (IOM) in 2011 was used. As a study item, firstly, the degree of satisfaction of vitamin D using serum $250 H D$ concentration was determined. Second, it divided into VD deficient group and non-deficient group age, sex, disease duration, psoriatic arthritis type, blood biochemical test, presence of active VD administration, presence or absence of active type VD coating for skin, presence or absence of MTX - BIO, Osteoporosis · Percentage of osteopenia - The presence or absence of vulnerability fracture history was compared between both groups.

Results: Mean serum 25OHD concentration in patients with PsA was 16.4 $\pm 6.3 \mathrm{ng} / \mathrm{ml}$ and serum $25 \mathrm{OHD}$ deficiency was observed in 134cases (74.4\%). Factors that showed significant differences between the two groups (VD deficient group/normal group) were age (54.4/59.0y.o. $\mathrm{p}=0.032$ ), gender (female rate) $35.0 \% / 11.9 \%$ : $p=0.040$, ACPA negative rate $97.0 \% / 85.2 \%: p=0.010$, serum MMP-3 (69.0/98.4 ng/ml $\mathrm{p}=0.030)$, active vitamin $\mathrm{D}$ top coating use rate for skin $54.0 \% / 88.9 \%$ : $p=0.001$, Biologics treatment rate $49.3 \% / 11.1 \%: p<0.001$

Conclusions: $74.4 \%$ of patients with PsA had vitamin D deficiency.

In the vitamin d-deficient group, low age, high female rate, ACPA negative, low serum MMP-3, VD coating low use rate for skin, biological product high usage rate were significant.

Disclosure of Interest: None declared

DOI: 10.1136/annrheumdis-2018-eular.4822

\section{AB0950 MINIMAL DISEASE ACTIVITY IN REAL LIFE IN PSORIATIC ARTHRITIS}

S.B. Ureyen ${ }^{1}$, D. Solmaz ${ }^{1}$, N. Al Asoimi ${ }^{1}$, on behalf of PsArt-ID (Psoriatic ArthritisInternational Database), E. Dalkilic ${ }^{2}$, M. Can ${ }^{3}$, A. Erden ${ }^{4}$, C. Ozisler ${ }^{4}$, M. Cinar ${ }^{4}$, L. Kilic ${ }^{4}$, U. Kalyoncu,, S.Z. Aydin ${ }^{1}$, on behalf of PsArt-ID (Psoriatic ArthritisInternational Database). ${ }^{7} P s$ Art-ID, Ottawa, Canada; ${ }^{2} P s A r t-I D$, Bursa; ${ }^{3} P s A r t-I D$, Istanbul; ${ }^{4}$ PsArt-ID, Ankara, Turkey

Background: Minimal disease activity (MDA) is an important target in patients with psoriatic arthritis (PsA), however it is also criticised for having low threshold for patient reported outcomes (PRO).

Objectives: The aim of the study was to assess the prevalence of MDA components in patients with PsA and to evaluate disease characteristics and patterns in patients with or without MDA.

Methods: PsArt-ID (Psoriatic Arthritis- International Database) is a prospective, multicentre web-based registry (www.trials-network.org). PsA patients who had at least 1 year of disease duration were included for this analysis. Patients were considered in MDA when they met at least 5/7 of the MDA criteria (figure 1).

Abstract AB0950 - Table 1. The demographics and disease characteristics according to MDA

\begin{tabular}{lccc}
\hline & no MDA & MDA & p value \\
& $170 / 317(53.9)$ & $147 / 317(46.0)$ & \\
\hline Female & $109 / 188(58)$ & $79 / 188^{42}$ & 0.061 \\
Age (years) $^{*}$ & $50(40-59)$ & $51.5(37-60.5)$ & 0.924 \\
Education years $^{*}$ & $11(5-15)$ & $11(5-14)$ & 0.738 \\
Disease duration (months) & $95(66-155)$ & $88(59-155)$ & 0.843 \\
Nail involvement & $92 / 171(53.8)$ & $73 / 146^{50}$ & 0.500 \\
Dactylitis & $65 / 170(38.2)$ & $55 / 147(37.4)$ & 0.881 \\
Enthesitis & $35 / 170(20.6)$ & $16 / 147(10.9)$ & 0.022 \\
PsA clinical pattern & & & \\
Polyarthritis & $78 / 170(45.9)$ & $70 / 146(47.9)$ & 0.714 \\
Oligoarthritis & $66 / 170(38.8)$ & $50 / 146(34.2)$ & 0.415 \\
Monoarthritis & $1 / 170(0.6)$ & $9 / 146(6.2)$ & 0.007 \\
DIP joint involvement & $42 / 170(24.7)$ & $23 / 146(15.8)$ & 0.050 \\
Axial involvement & $79 / 170(46.5)$ & $56 / 146(38.4)$ & 0.171 \\
Arthritis mutilans & $0 / 170(0)$ & $1 / 146(0.7)$ & 0.462 \\
\hline
\end{tabular}

Results: In January 2018, 1283 patients from Turkey and 119 patients from Canada were recruited, 317 of whom had full data for MDA and were included in this analysis. The demographics, disease characteristics and patterns in patients with MDA achieved vs not are summarised in the table. There were no differences regarding demographics in both groups. The monoarthritis subtype (RR: 2.01, 95\% Cl: $1.579-2.559$ ), the absence of enthesitis (RR: $1.570,95 \% \mathrm{Cl}: 1.027-$ 2.398) and the absence of distal interphalangeal joint disease (RR: $1.1,95 \% \mathrm{Cl}$ : 1.001-1.25) were associated with higher probability of achieving MDA. Across different domains included in MDA, pain VAS $\leq 15$ and PtGA $\leq 20$ could less frequently be achieved even when MDA is fulfilled as $44.5 \%$ and $26.5 \%$ of patients respectively still did not fulfil these domains (figure 1). On the other hand, for patients that did not achieve MDA, the body surface area $(51.2 \%)$ and swollen joint count $(53.5 \%)$ domains could be achieved in the majority of the patients and 93.5\% of them had no enthesitis using the Leeds enthesitis index. Physician global assessment ( $>21 \mathrm{vs} \leq 20$ ) and BASDAI ( $>41 \mathrm{vs} \leq 40$, only for axial disease) had only moderate agreement with MDA (achieved or not) (kappa $=0.47$ $\mathrm{p}=0.05$ and kappa $=0.469, \mathrm{p}=0.072$; respectively).

All data were given $\mathrm{n} /$ total $\mathrm{n}$ (percentage $(\%)$ ) or median (first-third percentiles) ${ }^{*}$. MDA: minimal disease activity; PsA: Psoriatic Arthritis; DIP: distal interphalangeal.

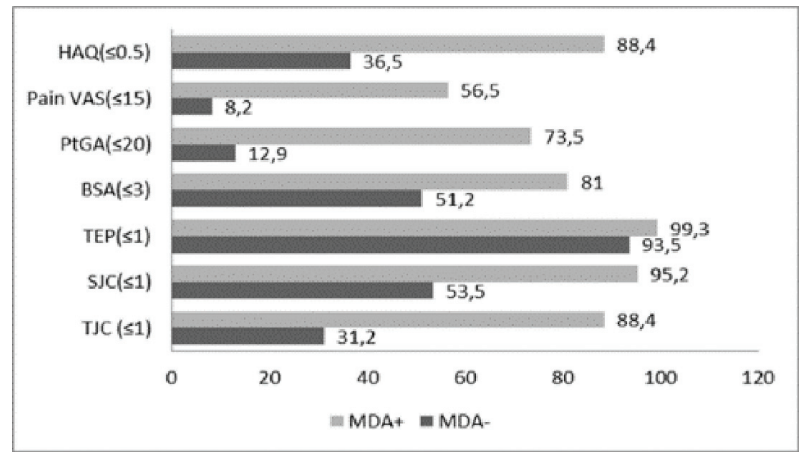

Abstract AB0950 - Figure 1. The distribution of all MDA domains in patients achieving MDA and patients not achieving MDA. TJC: tender joint counts; SJC: swollen joint counts; TEP: tender entheseal points; BSA: body surface area; PtGA: patient global activity; VAS: visual analogue scale; $\mathrm{HAQ}$ : Health Assessment Questionnaire.

Conclusions: The MDA criteria provide an objective target for treatment in trials and clinical practice; however in real life PROs are the most significant barriers to achieve MDA within all domains. Leeds enthesitis index was not able differentiate MDA, for being negative in the vast majority of the patients. Monoarthritis subtype is a good prognostic factor whereas DIP joint disease and history of enthesitis are poor prognostic factors to achieve MDA

Disclosure of Interest: None declared

DOI: 10.1136/annrheumdis-2018-eular.2729

\section{AB0951 ULTRASONOGRAPHIC ASSESSMENT OF NAIL IN PSORIATIC DISEASE FOUND A LINK BETWEEN NAIL DISORDER AND SOFT TISSUE SWELLING AROUND THE NAIL}

T. Okano ${ }^{1}$, K. Inui ${ }^{1}$, Y. Yamada ${ }^{1}$, K. Mandai ${ }^{1}$, K. Mamoto ${ }^{1}$, Y. Sugioka ${ }^{2}$, T. Koike ${ }^{2,3}$, H. Nakamura ${ }^{1} .{ }^{1}$ Department of Orhopedic surgery; ${ }^{2}$ Center for Senile Degenerative Disorders (CSDD), Osaka City University Graduate School of Medicine, Osaka; ${ }^{3}$ Search Institute for Bone and Arthritis Disease (SINBAD), Shirahama Foundation for Health and Welfare, Wakayama, Japan

Background: Although skin lesion is the most typical findings in patients with psoriasis ( $\mathrm{PsO}$ ), nail psoriasis is also one of the clinical manifestation. Moreover nail disorders in $\mathrm{PsO}$ are known as a risk factor for psoriatic arthritis (PsA). How ever, pathological feature and the relationship with inflammation of the soft tissue around the nail is unknown. ${ }^{1-2}$

Objectives: The aim of this study was to compare the soft tissue thickness around the nail in patients with $\mathrm{PsO}, \mathrm{PsA}$ and other rheumatic diseases by using ultrasonography.

Methods: Twenty-five $\mathrm{PsO} \cdot 35 \mathrm{PsA} \cdot 23$ rheumatoid arthritis (RA) $\cdot 28$ ulcerative colitis (UC) and 13 Crohn's disease (CD) patients performed ultrasonographic assessment in nail were included in this analysis. Ultrasonographic examination was performed by using $\mathrm{HI}$ VISION Ascendus (Hitachi Medical Corporation, Japan) with a multifrequency linear transducer (18-6 MHz) and the grey scale (GS) and power Doppler (PD) findings were assessed. The distance between the proximal nail fold on the dorsal side of the nail matrix and the nail bed on the volar side of the nail matrix was measured by electric calliper

Results: The distance between the proximal nail fold and the nail bed was 2.58 $\pm 0.56 \mathrm{~mm}$ in $\mathrm{PsA}$ and $2.55 \pm 0.58 \mathrm{~mm}$ in $\mathrm{PsO}$ patients $(p=0.603)$. Among the 60 patients who combined $\mathrm{PsO}$ and $\mathrm{PsA}$ patients, 41 patients with nail psoriasis and 19 patients without nail psoriasis was compared. The distance was 2.68 $\pm 0.62 \mathrm{~mm}$ in patients with nail psoriasis and $2.30 \pm 0.41 \mathrm{~mm}$ in without nail psoriasis $(p<0.001)$, which was also swelling compared with the RA, UC and CD group. 
Abstract AB0951 - Table 1. The thickness of proximal nail fold, nail bed and proximal nail fold + nail bed in patients with psoriasis, psoriatic arthritis and other rheumatic disease

\begin{tabular}{|c|c|c|c|}
\hline & $\begin{array}{l}\text { proximal nail } \\
\text { fold } \\
(\mathrm{mm})\end{array}$ & $\begin{array}{l}\text { nail bed } \\
(\mathrm{mm})\end{array}$ & $\begin{array}{l}\text { proximal nail } \\
\text { fold } \\
+ \text { nail bed } \\
(\mathrm{mm})\end{array}$ \\
\hline Psoriasis $(n=25)$ & $1.23 \pm 0.27$ & $\begin{array}{r}1.33 \\
\pm 0.47\end{array}$ & $2.55 \pm 0.58$ \\
\hline Psoriatic arthritis $(n=35)$ & $1.33 \pm 0.35$ & $\begin{array}{c}1.25 \\
\pm 0.38\end{array}$ & $2.58 \pm 0.56$ \\
\hline $\begin{array}{l}\text { Psoriasis or psoriatic arthritis with nail psoriasis } \\
(\mathrm{n}=41)\end{array}$ & $1.34 \pm 0.34$ & $\begin{array}{c}1.36 \\
\pm 0.45\end{array}$ & $2.68 \pm 0.62$ \\
\hline $\begin{array}{l}\text { Psoriasis or psoriatic arthritis without nail } \\
\text { psoriasis }(n=19)\end{array}$ & $1.18 \pm 0.27$ & $\begin{array}{c}1.11 \\
\pm 0.29\end{array}$ & $2.30 \pm 0.41$ \\
\hline Rheumatoid arthritis $(n=23)$ & $1.14 \pm 0.27$ & $\begin{array}{c}1.14 \\
\pm 0.33\end{array}$ & $2.27 \pm 0.46$ \\
\hline Ulcerative colitis $(n=28)$ & $1.21 \pm 0.28$ & $\begin{array}{c}1.22 \\
\pm 0.33\end{array}$ & $2.43 \pm 0.49$ \\
\hline Crohn's disease $(n=13)$ & $1.11 \pm 0.25$ & $\begin{array}{c}1.14 \\
\pm 0.37\end{array}$ & $2.25 \pm 0.49$ \\
\hline
\end{tabular}

Conclusions: Soft tissue thickness around the nail in patients with PsO and PsA was compared with other rheumatic diseases by ultrasonographic assessment. In patients with PsO and PsA with nail psoriasis, soft tissue swelling around nail was observed.

\section{REFERENCES:}

[1] Sandobal C, Carbó E, Iribas J, et al. Ultrasound nail imaging on patients with psoriasis and psoriatic arthritis compared with rheumatoid arthritis and control subjects. J Clin Rheumatol. 2014;20:21-4.

[2] Aydin SZ, Castillo-Gallego C, Ash ZR, et al. Ultrasonographic assessment of nail in psoriatic disease shows a link between onychopathy and distal interphalangeal joint extensor tendon enthesopathy. Dermatology. 2012;225:231-5.

Acknowledgements: We wish to thank Tomoko Nakatsuka for clinical assistant, Setsuko Takeda, Emi Yamashita and Yuko Yoshida for their special efforts as a sonographer and collecting data.

Disclosure of Interest: None declared

DOI: 10.1136/annrheumdis-2018-eular.2895

\section{AB0952 HIGH PREVALENCE OF INFLAMMATORY AND NON- INFLAMMATORY LIVER AND GASTROINTESTINAL DISEASES IN YOUNG PATIENTS WITH PSORIATIC ARTHRITIS: A HOSPITAL-BASED STUDY}

N. Batkaeva ${ }^{1}$, E. Batkaev ${ }^{2}$, T. Korotaeva ${ }^{3} .{ }^{1}$ Dermatology, Peoples' Friendship University of Russia (RUDN University); ${ }^{2}$ Dermatology, Peoples' Friendship University of Russia (RUDN University); ${ }^{3}$ Research Institute of Rheumatology n. a. V. A. Nasonova, Moscow, Russian Federation

Background: Psoriatic arthritis (PsA) is associated with numerous comorbidities, including gastrointestinal (GI) and liver diseases (LD). But there is limited data about the prevalence of these disorders among patients (pts) with PsA and severe psoriasis ( $\mathrm{PsO}$ ) in Russian population.

Objectives: to evaluate the prevalence of LD and GIT comorbidity in a hospitalbased cohort of PsA pts.

Methods: 417 (304 Male (M.)/113 Female (F.) PsA pts, according the CASPAR criteria, mean age $38.5 \pm 11.3 / 36.1 \pm 11.0$ years (yrs) accordingly, PASI 49,4 40.56 , PsA duration 6.6 \pm 7.4 years were included. PsA pts with all GIT and LD, including Diseases of oesophagus, stomach and duodenum (K20-K31), Disorders of gallbladder, biliary tract and pancreas (K80-K87), Alcoholic and toxic liver disease (K70-K77) (LD), Viral hepatitis (B15-B19) (VH), non-infectious enteritis and colitis (K55-K63) NEC) were identify in the hospital Database and coding by International Statistical Classification of Disease and Related Health Problems (ICD-10) between 2010-2015 years. $\mathrm{M} \pm \mathrm{m}$, t-test, (\%) were calculated. All $\mathrm{p}<0.05$ were considered to indicate statistical significance.

Results: 229 (159- M./70 - F.) out of 417 pts (54.9\%) had LD and GIT disorders. Gallbladder, biliary tract and pancreas disease coding as K80-K87 were found in significantly more cases in F. compare to M. pts - in 26 out of 70 pts (37.4\%) and in 31 out of 159 pts $(19.4 \%)$ accordingly $(p<0.05)$. NEC coding as K55-K63 was found in M. only - in 1 out of $159(0.62 \%)$ pts. Diseases of oesophagus, stomach and duodenum coding as K20-K31 were found in 96 out of 229 pts (42\%). All of the alcoholic, toxic and viral liver disease were found in 75 out of 229 pts $(32.75 \%)$. LD coding as K70-K77 were found in 33 out of 75 pts (44\%). VH coding as B15-B19 were found in 42 out of 75 pts (56\%). No significantly gender differences were found in those group of pts.

Conclusions: GIT and LD were found in more than half of young pts with PsA and severe PsO. That information should be taken in account during the choice of safety therapy in this group of pts.

Disclosure of Interest: None declared

DOI: 10.1136/annrheumdis-2018-eular.1562

\section{AB0953 PSAID-12 CAN BE USED TO DETERMINE THE ANTI-TNF TREATMENT DECISION IN THE PSORIATIC ARTHRITIS REGISTRY}

U. Kalyoncu, S. Kiraz, S. Apras Bilgen, O. Karadag, A. Akdogan, L. Kilic, A. Erden, B. Armagan, A. Sari, I. Ertenli. Hacettepe University, Department of Internal Medicine, Division of Rheumatology, Ankara, Turkey

Background: Psoriatic Arthritis Impact of Disease (PsAID-12) score has 12 questions and each question has its own weight. PsAID-12 is developed to be used in daily practice. However, in the daily practice, there has been no information on the utilisation of determining the response of the biological DMARD treatment.

Objectives: The assessment of utilisation of PsAID-12 for PsA patients on determination of the efficiency and inefficiency of anti-TNF treatment in a biological registry.

Methods: In this study patients were taken from Hacettepe University biological database (HUR-BIO). Since January 2013 PsAID-12 score was built in HUR-BIO database. PsAID-12 score was known for 116 patients before starting off the first anti-TNF treatment and 88 patients whose PsAID-12 score was 4 and above were included in the enquiry. Overall, 70 PsA patients included to analysis. Demographic data before anti-TNF treatment of PsA patients were noted. The decision of continuation, stopping or switching to another anti-TNF drugs were performed by both clinicians and the patients agreement. According to baseline evaluation, decrease of $20 \mathrm{~mm}$ and above on pain-VAS score and PGA, improvement of 0.22 unit and above on HAQ-DI score, or decrease of 1.2 unit and above on DAS-28 score were considered favourable to the anti-TNF treatment. Stopping or switching the anti-TNF treatments due to inefficiency was definitely a negative response. Pain-VAS score being under $15 \mathrm{~mm}$ or below, global-VAS score being $20 \mathrm{~mm}$ and below, HAQ-DI score being 0.5 and below, DAS-28 score being 2.6 and below were determined as targeted goals. Changes were analysed comparing to baseline level in PSAID-12 score, in compliance with the favourable and unfavourable responses to Anti-TNF treatments. In determining the response of the treatment, standardised response mean (SRM) was used.

Results: Seventy $(78.6 \%$ female) patients were analysed, mean age was 45.5 (12.0). Mean follow-up duration was 18.3 (12.6) months, and total of 213 clinical visits were performed, median $3^{1-8}$ control visits were done. At baseline, the mean (SD) DAS-28 4.07 (1.22), HAQ-DI 0.86 (0.53), pain-VAS 6.9 (2.1), PGAVAS 6.4 (1.7), and PsAID-12 6.6 (1.5) were as follows. Anti-TNF treatments were stopped due to inefficacy in $43 / 210(20.5 \%)$ outpatient visit during the follow-up period. The results of anti-TNF stopped and continuing patients; $\triangle$ PsAID-12 were 0.38 (1.71), and 3.12 (2.14), respectively and PsAID-12 baseline/control visits $0.96(0.29)$ vs $0.50(0.33)$, respectively. Level of favourable response and achieving to goal according to $\triangle$ PsAID-12 and PsAID-12 Baseline/control visit were shown table 1. On the follow up visits, among measured parameters one of the highest SRM was detected in PSAID-12; PsAID-12 (1.10), DAS-28 (1.14), PGA (0.88), Pain (0.85), and HAQ-DI (0.51), respectively.

Abstract AB0953 - Table 1. Goals and responses of Anti-TNF treatment

\begin{tabular}{|c|c|c|c|c|}
\hline & & & $\triangle \mathrm{P}_{\mathrm{s}}$ AID-12 & $\begin{array}{l}\text { PsAID-12 } \\
\text { Baseline/control }\end{array}$ \\
\hline \multirow{8}{*}{$\begin{array}{l}\text { Level of } \\
\text { favorable } \\
\text { response to anti- } \\
\text { TNF treatments }\end{array}$} & \multirow[t]{2}{*}{$\Delta$ Pain $\geq 20 \mathrm{~mm}$} & Yes $n=136$ & $3.4(1.9)$ & $0.47(0.33)$ \\
\hline & & No $n=77$ & $1.1(1.9)$ & $0.81(0.34)$ \\
\hline & \multirow[t]{2}{*}{$\triangle P G A \geq 20 \mathrm{~mm}$} & Yes $n=133$ & $3.4(2.1)$ & $0.45(0.33)$ \\
\hline & & No $n=80$ & $1.2(2.0)$ & $0.84(0.31)$ \\
\hline & \multirow[t]{2}{*}{$\triangle \mathrm{HAQ}-\mathrm{DI} \geq 0.22$} & Yes $n=110$ & $3.5(2.0)$ & $0.44(0.29)$ \\
\hline & & No $n=103$ & $1.6(2.1)$ & $0.74(0.38)$ \\
\hline & \multirow[t]{2}{*}{$\Delta$ DAS- $28 \geq 1.2$} & Yes $n=122$ & $3.5(2.1)$ & $0.44(0.31)$ \\
\hline & & No $n=70$ & $1.2(1.8)$ & $0.80(0.32)$ \\
\hline \multirow{8}{*}{$\begin{array}{ll}\text { Level of } \\
\text { achieving the } \\
\text { goal of PsA } \\
\text { treatment }\end{array}$} & \multirow[t]{2}{*}{ Pain $\leq 15 \mathrm{~mm}$} & Yes $n=57$ & $4.3(2.1)$ & $0.28(0.32)$ \\
\hline & & No $n=156$ & $1.9(2.1)$ & $0.71(0.32)$ \\
\hline & \multirow[t]{2}{*}{$\mathrm{PGA} \leq 20 \mathrm{~mm}$} & Yes $n=68$ & $4.2(2.1)$ & $0.28(0.29)$ \\
\hline & & No $n=145$ & $1.8(2.0)$ & $0.74(0.32)$ \\
\hline & \multirow[t]{2}{*}{$\mathrm{HAQ}-\mathrm{DI} \leq 0.5$} & Yes $n=136$ & $3.5(2.1)$ & $0.43(0.32)$ \\
\hline & & No $n=77$ & $0.9(1.7)$ & $0.89(0.28)$ \\
\hline & \multirow[t]{2}{*}{ DAS- $28<2.6$} & Yes $n=118$ & $3.1(2.3)$ & $0.48(0.35)$ \\
\hline & & No $n=85$ & $1.7(2.2)$ & $0.75(0.36)$ \\
\hline
\end{tabular}

Conclusions: Having 3.5 unit or $50 \%$ decrease in the PSAID-12 score indicates a favourable response to anti-TNF treatment, 4 unit or $70 \%$ decrease indicates leve 